COMUNICACIÓN CIENTÍfICA IX CONGRESO NACIONAL DE LA SOCIEDAD CIENTÍFICA ESPAÑOLA DE ENFERMERÍA - SCELE. Mayo de 2018. UNIVERSIDAD DE ALICANTE.

\title{
PRESCRIPCIÓN ENFERMERA EN EUROPA. ANÁLISIS DIFERENCIADO DE LOS DIFERENTES PAÍSES.
}

\section{Rodrigo Santos Gómez}

Ministerio de Defensa. III Bandera Paracaidista Ortíz de Zarate. Brigada Paracaidista. Jabalí Nuevo. Murcia.

E-mail: rodrigosg4@gmail.com 


\section{PALABRAS CLAVE:}

Prescripción Enfermera, Enfermería, Europa.

Introducción. La prescripción de medicamentos es un acto sanitario, no solo médico. Se prescribe dentro del ejercicio de las competencias y responsabilidades, según marca la ley. La diferencia entre países radica en competencias reconocidas a cada especialidad (enfermería), y en las leyes adoptadas en función de la asunción de dichas responsabilidades por diversos motivos (económicos, organización de trabajo, escasez de personal, seguridad jurídica, etc). En algunos países ya es un hecho la prescripción enfermera, en otros se encuentra en desarrollo legislativo (como es el caso de España), y en otros tantos es un tema por desarrollar. Existe un compromiso común por directiva europea de desarrollarla, cuya principal razón es tener una mejor atención sanitaria y de calidad respecto al acceso a los medicamentos. Para su desarrollo se relacionan los conceptos de enfermera de practica avanzada/especialista.

Metodología. Se trata de una revisión descriptiva bibliográfica. Las bases de datos consultadas han sido: Medline, SCOPUS, WoS, Lilacs, COCHRANE, CINAHL, Google Scholar e Instituto de Investigación Enfermera (José Luis Cobos). Los descriptores utilizados han sido combinaciones de nomenclatura enfermera y prescriptora. Los artículos seleccionados han sido los de acceso gratuito, en diferentes idiomas, desde 2006 hasta la actualidad y de tipo revisión sistemática. Ha habido numerosas limitaciones para encontrar información en muchos países de la Unión Europea (UE).

Resultados Los países que actualmente cuentan con prescripción enfermera son:

- Suecia (pioneros en 1994): curso de 10-20 semanas en función de especialización y prescripción independiente y colaborativa. Autoriza a matronas, enfermeras de geriatría y enfermeras de distrito

- RU (1998): acreditar 3 años de experiencia clínica, realizar curso 3-6 meses y días de actividad clínica supervisada por médico. Prescripción independiente, suplementaria y bajo protocolo de grupo. Autoriza a todas las enfermeras para prescribir

- Irlanda (2007): requieren el mismo período de formación que en Suecia y prescripción colaborativa restrictiva al tiempo que se está trabajando

- Estonia (2009): 120 horas de formación en farmacología. Prescripción colaborativa. Autoriza a las enfermeras de familia para prescribir

- Francia (2007): formación del grado universitario y prescripción colaborativa e independiente. Autoriza a todas las enfermeras para prescribir

- España (2006): Prescripción colaborativa. RD 954/2015. Autonomía para productos sanitarios no sujetos a prescripción médica, colaborativa para medicamentos que requiere prescripción médica previo diagnóstico y prescripción médica explícita, enfermero no acreditado solo puede administrar previa prescripción.

- Finlandia (2010): 1125 horas de formación entre práctica y teoría y prescripción colaborativa. Autoriza a las enfermeras de salud pública para prescribir

Discusión y conclusiones. A pesar del crecimiento que está teniendo aún hay obstáculos para su desarrollo e implementación. Los principales problemas son: de colaboración en los equipos de salud por tensiones competenciales; insuficientes conocimientos de los profesionales de enfermería sobre farmacología; facilidad para ser manipuladas por la industria farmacéutica con el resultado de incrementos de los costes y mayor utilización inapropiada de medicamentos; y una dedicación excesiva a las tareas prescriptoras abandonando las demás actividades tradicionales de la profesión de enfermería. La prescripción enfermera es un acto que contribuye a la major calidad de los cuidados. 